\title{
Are angiotensin converting enzyme (ACE1/ ACE2) gene variants associated with the clinical severity of COVID-19 pneumonia? A single- center cohort study
}

\begin{abstract}
Objective: The impact of the coronavirus disease 2019 (COVID-19) pandemic has been unceasingly ongoing worldwide. Recent bioinformatics analysis and epidemiologic studies have highlighted that the functional polymorphisms on the angiotensin converting enzyme (ACE) gene may have an impact on the clinical progress of COVID-19. In this study, we aimed to determine the impact of the $A C E 1$ gene I/D polymorphism and ACE2 peptidase-2 domain variants on disease severity.
\end{abstract}

Methods: Hundred patients with confirmed COVID-19 related pneumonia [50 patients with severe disease in intensive care unit (ICU) and 50 patients not in ICU] were compared on the basis of genetic and clinical characteristics. Genomic DNA was purified from peripheral blood lymphocytes with an automated QIA symphony DSP DNA Mini-Kit. The Sanger sequencing analysis was performed. The frequencies of ACE1 gene polymorphism and ACE2 PD variants were compared in patients hospitalized in ICU and those not in ICU. The Statistical Package for Social Sciences version 22.0 was used for statistical analysis.

Results: The sequencing analysis of the ACE2 gene exon 1 and 2 revealed none of the polymorphisms investigated or any other variants in the present cohort. The frequencies of the ACE1 ID, DD, and II genotypes were $51 \%, 31 \%$, and $18 \%$, respectively. The frequency of the D allele was similar between the ICU and non-ICU groups (50.4\% versus $49.6 \%$ ). Older age and the presence of advanced stage radiologic abnormalities on admission were detected as independent predictors of ICU requirement.

Conclusion: No effect of any ACE1 gene polymorphism on predicting ICU requirement was detected. To the best of our knowledge, this is the first study investigating the impact of ACE gene polymorphisms on clinical severity of COVID-19 in a Turkish cohort.

Keywords: angiotensin converting enzyme, gene polymorphism, coronavirus disease 2019 severity, severe acute respiratory syndrome coronavirus 2

\section{INTRODUCTION}

The severe acute respiratory syndrome coronavirus 2 (SARS-CoV-2) infection emerged in Wuhan, China, in December 2019 and spread to other countries and even continents rapidly within a short period of time. The European population not only had a higher incidence of coronavirus disease 2019 (COVID-19), but also had a higher mortality rate than the Asian population (1). The defined geographical differences in the COVID-19 pattern (in terms of prevalence and mortality) may arise from ethnic/genetic factors in addition to socio-economic, politic, and cultural (behavioral) characteristics of the populations (2).

COVID-19 has a wide range of clinical spectrum from asymptomatic to life threatening infection. Although the pathogenesis is not clear enough yet, older age, hypertension, cardiovascular disease, and diabetes mellitus have been previously defined as predictors of severity (3). The renin angiotensin aldosterone system (RAAS) was reported to have an important role in the pathogenesis of COVID-19 (4). ACE1 and ACE2 have a critical role in maintaining the homeostasis of RAAS (5). The down-regulation of ACE2 expression leads to increased level of angioten-

\section{ORIGINAL INVESTIGATION}

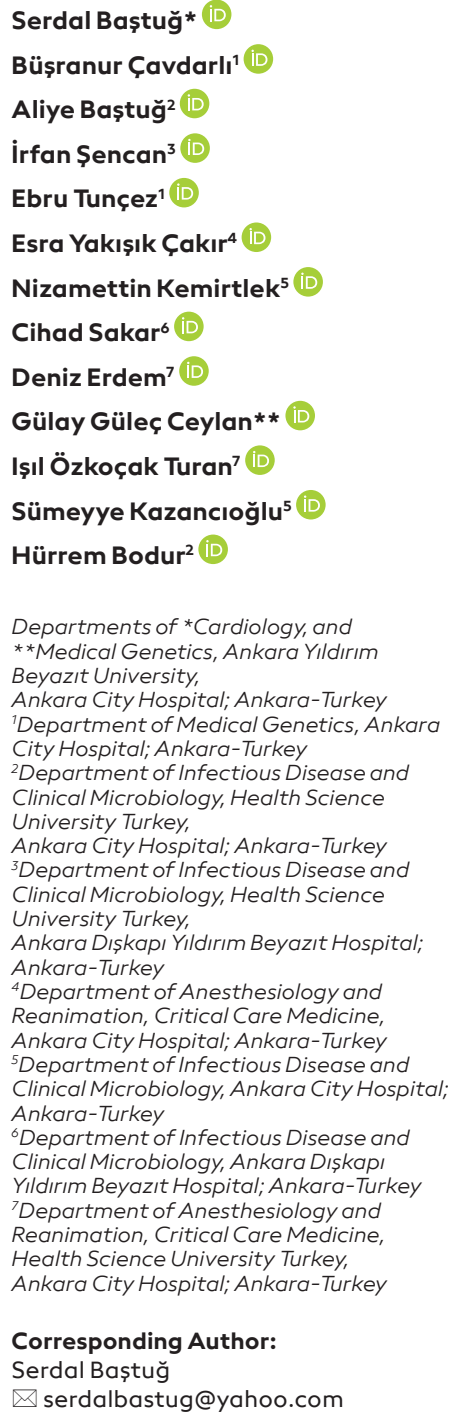

Corresponding Author:

Serdal Baștuğ

$\triangle$ serdalbastug@yahoo.com

Accepted: September 2, 2021 Available Online Date: December 8, 2021

Cite this article as: Baștuğ $S$, Çavdarlı B, Baştuğ A, Șencan I, Tunçez E, Yakıșık Çakır E, et al. Are angiotensin converting enzyme (ACE1/ACE2) gene variants associated with the clinical severity of COVID-19 pneumonia? A single-center cohort study. Anatol J Cardiol 2022; 26: 133-40.

DOI: 10.5152/AnatolJCardiol.2021.502 
sin-II (Ang-II), which leads to increased vascular permeability, pulmonary edema, and apoptosis of the bronchi alveolar epithelial cells (5). Consequently, they all contribute to lung injury and fibrosis (5-7). ACE1 gene insertion/deletion (ID) and especially deletion/deletion (DD) polymorphisms are related to increased levels of ACE1 and Ang-II. ACE1 DD polymorphism was also reported to be associated with hypertension and acute respiratory distress syndrome (7).

It has been suggested that some polymorphisms (S19P, I21V, E23K, K26R, T27A, N64K, T92I, Q102P and H378R) located in the gene region encoding the ACE2 peptidase domain (PD), which binds SARS-CoV-2, may increase the risk of infection with the virus (8). We hypothesized that ACE1 DD polymorphisms and ACE2 gene PD domain variants would increase susceptibility, and thus, lead to a genetic predisposition for severe lung injury in patients with COVID-19 in a Turkish population. To clarify this issue, $A C E 1$ gene l/D polymorphism and ACE2 PD variants were examined in addition to demographic and clinical factors that may be related to disease severity in this study.

\section{METHODS}

Study design and participants

This study was approved by the Ethics Board of our institution (No. E1-20-655). All consecutive 100 patients with laboratory-confirmed COVID-19 with pneumonia admitted to the tertiary hospital from March to May 2020 were enrolled. Fifty consecutive patients hospitalized in the intensive care units (ICU) and 50 consecutive patients hospitalized in wards were included in the study. The World Health Organization interim guidance was used for the diagnosis and grouping of the patients as severe/critical and non-severe (9). Patients in need of treatment in the ICU at any time of the hospitalization (on admission or during follow-up) (ICU group) and those followed up with mild disease in the infectious disease ward (non-ICU group) were compared in terms of genetic polymorphisms. The oro/ nasopharyngeal swab samples were obtained for SARS-CoV-2 reverse transcription-polymerase chain reaction (RT-PCR) test from the patients. Data including demographic, clinical, and radiological investigations of the patients were extracted from case follow-up forms and hospital electronic records.

Genetic analyses

Informed consent was obtained from patients who volunteered to participate in the study, and peripheral blood (2-3

\section{HIGHLIGHTS}

- The frequency of D allele was similar between patients in intensive care unit (ICU) and those not in ICU with coronavirus disease 2019 (COVID-19).

- Angiotensin converting enzyme (ACE1) gene I/D polymorphisms have no effect on predicting ICU needs in COVID-19.

- $A C E 2$ peptidase domain (PD) variants were not detected in the present COVID-19 cohort.

- ACE1 gene polymorphism and ACE2 PD variants did not have any impact on poor prognosis.

- Older age and the extensive lung involvement on admission are severity predictors.
$\mathrm{mL}$ ) was taken into an ethylenediamine tetraacetic acid tube for genetic analyses. Genomic deoxyribonucleic acid (DNA) was purified from peripheral blood lymphocytes with an automated QIA symphony DSP DNA Mini Kit (QIAGEN Inc., Germany).

\section{ACE2 exon 1 and exon 2 Sanger sequencing}

Since 8 of the variants increasing the risk of disease and 12 of the possible protective variants were localized on exon 1 and 2 of $A C E 2$ gene, we sequenced only these two exons. PCR and sequencing of the exon 1 and exon 2 of ACE2 were performed using the following primers: $A C E 2$ exon 1 forward primer 5' CCCAACCCAAGTTCAAAGG 3'; and reverse primer 5' GGAGGCAAACATCCAATCTC 3', ACE2 exon 2 forward primer 5' GGGAAAACCAGGCAATAGG 3'; and reverse primer 5' TCTTGGGATCAATGCTAAAATG 3', respectively. PCR reaction was conducted with $15 \mathrm{pmol} / \mu \mathrm{L}$ of each primer, 1xTaq PCR master mix (Qiagen Inc., Germany), and $0.5 \mu \mathrm{g} / \mu \mathrm{L}$ genomic DNA in a total volume of $25 \mu \mathrm{L}$. PCR was performed as follows: $94^{\circ} \mathrm{C}$ for $2 \mathrm{~min} ; 40 \mathrm{cycles}$ of $94^{\circ} \mathrm{C}$ for $30 \mathrm{sec}, 55^{\circ} \mathrm{C}$ for $30 \mathrm{sec}, 72^{\circ} \mathrm{C}$ for $1 \mathrm{~min}$, and $72^{\circ} \mathrm{C}$ for $5 \mathrm{~min}$. PCR fragments were sequenced with the forward and/or reverse primers using an ABI Big Dye Terminator v3.1 Cycle Sequencing Kit (Applied Biosystems, Inc., Foster City, CA, USA) on an ABI Genetic Analyzer 3500XL (Applied Biosystems). Sequence analysis of both exon 1 and 2 of the ACE2 gene were evaluated by the SeqScape software ${ }^{\circledR} 2.0$ (Applied Biosystems).

\section{Angiotensin converting enzyme (ACE1) polymorphism} To determine the ACE1 insertion/deletion genotype (rs1799752) of the patients, a genomic DNA fragment in intron 16 of the ACE gene was amplified. PCR amplification products were obtained using a 1XTaq PCR master mix (Qiagen Inc., Germany), $1 \mu \mathrm{g}$ genomic DNA, $50 \mathrm{pmol} / \mu \mathrm{l}$ primers with 5 min of denaturation at $94^{\circ} \mathrm{C}$, followed by 30 cycles of $1 \mathrm{~min}$ at $94^{\circ} \mathrm{C}, 1 \mathrm{~min}$ at $58^{\circ} \mathrm{C}$, and $1 \mathrm{~min}$ at $72^{\circ} \mathrm{C}$. Reaction was terminated at $72^{\circ} \mathrm{C}$ for $2 \mathrm{~min}$. The forward and reverse primers used were 5' CTGGAGACCACTCCCATCCTTTCT 3' and 5' GATGTGGCCATCACATTCGTCAGAT 3', respectively. Fragments without insertion ( $D$ allele) and with insertion (I allele) of 190 and 490 base pair (bp), respectively, were separated using capillary gel electrophoresis (QIAxcel Advanced System, Qiagen Inc., Germany).

PCR amplification using a primer pair that recognizes insertion-specific sequence identifies $4 \%-5 \%$ of ID genotypes that have been misclassified as DD when only a flanking primer pair was used. To increase the specificity of DD genotyping, we used another primer pair recognizing the insertion-specific sequence reported before (10). Thus, PCR amplifications were performed with an insertion-specific primer pair 5' TGGGACCACAGCGCCCGCCACTAC 3' and 5' TCGCCAGCCCTCCCATGCCCATAA 3'), within $25 \mu \mathrm{l}$ reactions; 1xTaq PCR master mix (Qiagen Inc., Germany), $0.5 \mu \mathrm{g}$ genomic DNA, $50 \mathrm{pmol} / \mu \mathrm{l}$ of primers, with $1 \mathrm{~min}$ of denaturation at $94^{\circ} \mathrm{C}$, followed by 30 cycles of $30 \mathrm{~s}$ at $94^{\circ} \mathrm{C}, 45 \mathrm{~s}$ at $67^{\circ} \mathrm{C}$, and 2 min at $72^{\circ} \mathrm{C}$. Only the I allele produced a $335-b p$ amplicon. The 335-bp fragment was identified on capillary gel electrophoresis (QIAxcel Advanced System, Qiagen Inc., Germany). The reaction yields no products in the samples of 
DD genotype. All types of the genotypes are visualized on Figure 1 for explanatory information.

ACE1 polymorphism analysis results were evaluated as DD, ID, and II genotype and included in the statistical analysis according to both allele frequencies and genotype ratios.

Statistical analysis

The statistical analysis was performed using the Statistical Package for Social Sciences for Windows version 22.0 software program (SPSS Inc, IBM Corporation, Armonk, NY, USA). The Kolmogorov-Smirnov test was used to determine the normality of the variables. Descriptive analysis is presented via median [interquartile range (IQR)] for non-normally distributed variables and mean \pm standard deviation for normally distributed variables. Genetic, demographic, and radiologic variables were compared between the groups using the Mann-Whitney $U$ test for non-parametric variables. The Pearson chi-squared test or the Fisher's Exact test was used for comparing categorical variables. The Kruskal Wallis test was used to compare more than two groups. Binary logistic regression analysis was used to determine the predictors of the ICU need. Odds ratios and their $95 \%$ confidence intervals (CI) were calculated for binary outcomes. Statistical significance was set as $p<0.05$.

\section{RESULTS}

Clinical and demographic characteristics

A total of 100 hospitalized patients with the diagnosis of laboratory confirmed (RT-PCR positive) COVID-19 pneumonia were enrolled. The median age was 51 years (min-max, 21-87), and $59 \%$ were men. The median duration of symptoms prior to admission was 3 days (min-max, $0-20$ ). The

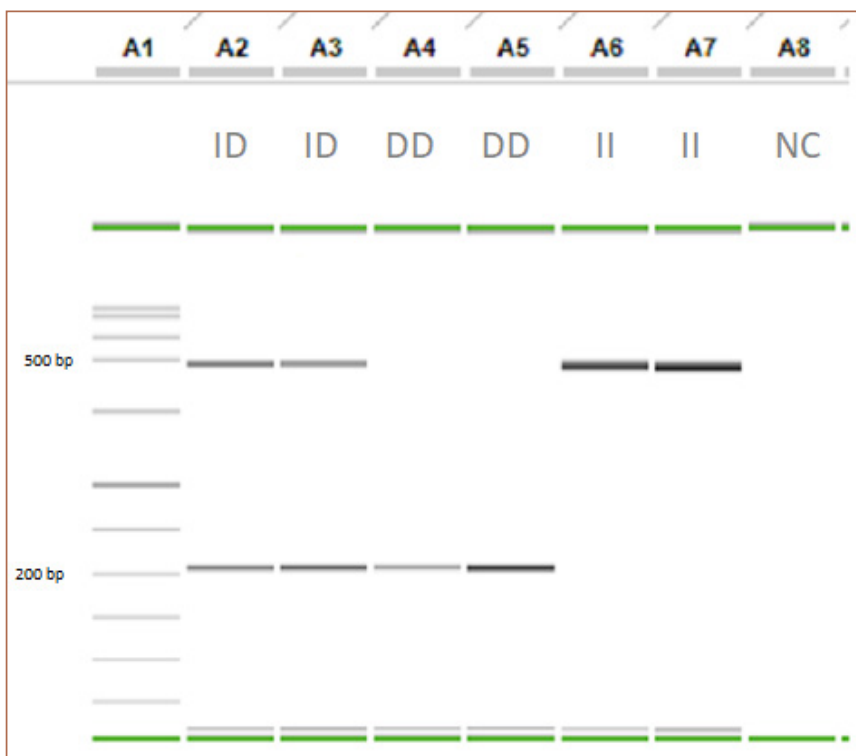

Figure 1. The angiotensin converting enzyme 1 deletion/insertion polymorphisms are visualized on the electropherogram. A1 column shows the deoxyribonucleic acid ladder. Polymerase chain reaction products of deletion and insertion alleles are 190 bp and 490 bp, respectively.

bp - base pair, DD - deletion/deletion, II - insertion/insertion, ID - insertion/ deletion, NC - negative control most common comorbidities of the patients were hypertension, diabetes mellitus, chronic obstructive pulmonary disease, and coronary artery disease with the frequency of $33 \%, 29 \%, 16 \%$, and $14 \%$, respectively. The blood types were similar between the ICU and non-ICU groups (Table 1). In addition, no significant differences were detected between patients with various ACE1 I/D polymorphisms (ACE1 II, ID, and DD) in terms of blood types (Table 2). As expected, the sequential organ failure assessment score was significantly higher in ICU patients than in non-ICU patients $(p<0.001)$. The mean acute physiology and chronic health evaluation II score was $8.33 \pm 10.4$ on the day of ICU admission. Critically ill patients who were in need of ICU support were significantly older [median age 64 years (min-max, 23-75) vs. 43.5 years (min-max, 23-75), $p<0.001]$ when compared with the non-ICU group. Furthermore, patients in the ICU group had significantly more underlying comorbidities [42 (84\%) vs. 17 $(34 \%) ; p<0.001]$. In this study, the presence of comorbidity, in terms of hypertension, diabetes mellitus, and coronary artery disease, was all found significantly more frequent in the ICU group ( $p<0.001, p=0.004$, and $p=0.021$, respectively). The advanced stage radiologic abnormalities, defined as bilateral multilobar ground glass opacities, mainly in the peripheral areas of the lungs and consolidation, were more frequent in the ICU group [96\% ( $n=48)$ vs. 54\% $(n=27) ; p<0.001]$ (Table 1). Single logistic regression analysis revealed that older age, comorbidities including hypertension, diabetes mellitus, and coronary artery disease, and the presence of advanced stage radiologic abnormalities were all significant risk factors for ICU requirement. Older age and the presence of advanced stage radiologic abnormalities on admission were independent predictors of ICU requirement (Table 3).

Results of genetic analysis

ACE2 gene exon 1 and 2 Sanger sequencing analysis did not reveal either investigated polymorphisms or any other variants in any patient in this study. There is no healthy population database to determine the frequency of gene variants in the Turkish population. To evaluate the analysis result, the data of 125 patients who had undergone whole exome sequencing analysis in pre-COVID era with different indications were retrospectively analyzed for ACE2 gene exon 1 and 2 variants. No variant was detected in any of the patients (unpublished data).

Of the patients, $51 \%$ had ACE1 ID polymorphisms, and $31 \%$ had $A C E$ DD and $18 \%$ had $A C E$ II polymorphisms. When the patients in the ICU and non-ICU groups were compared, there was no significant difference on the basis of any of the ACE1 gene polymorphisms. The frequency of ' $I$ ' and ' $D$ ' allele was $43.5 \%$ and $56.5 \%$ in our study group, and it was not different between the ICU and non-ICU groups ( $p>0.05,50.4 \%$ vs. $49.6 \%$ for the ' $D$ ' allele) (Table 1 ).

Distribution of demographic, clinical, and radiological variables according to ACE1 polymorphism was similar between the groups (Table 2). There was no significant effect of ACE1 ID, DD, and II polymorphisms on the risk of ICU need among patients in both groups (Table 4). ICU requirement was determined in $61.1 \%$ of the patients with ACE1 II polymorphism, 
Table 1. Demographic, clinical, and genetic polymorphism characteristics of the patients

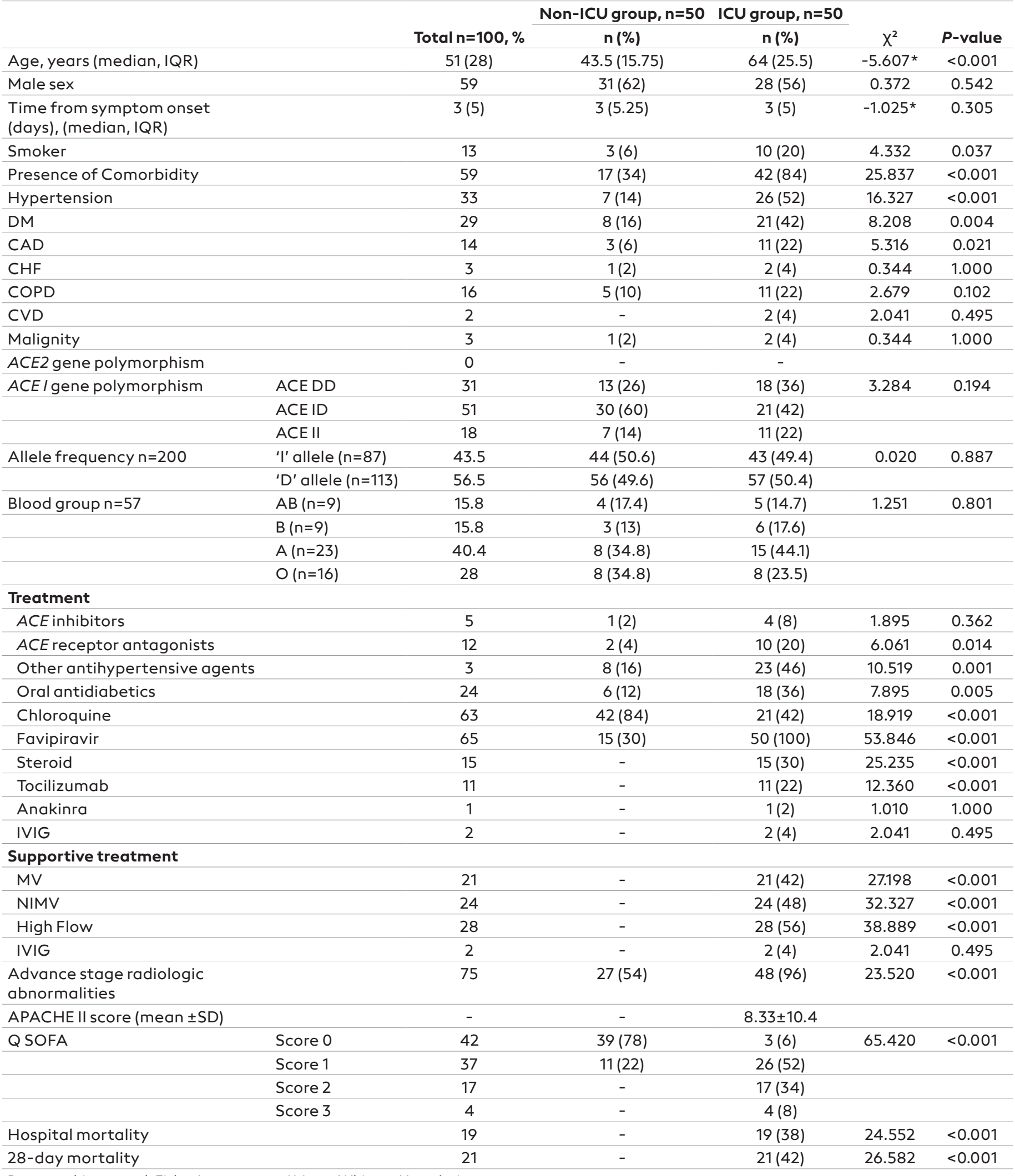

Pearson chi-squared, Fisher's exact test, *Mann-Whitney $U$ analysis,

ACE - angiotensin converting enzyme, APACHE II - acute physiology and chronic health evaluation II, COPD - chronic obstructive pulmonary disease, ICU - intensive care unit, IQR - interquartile, ID - insertion/deletion, II - insertion/insertion, DD - deletion/ deletion, IVIG - intravenous immunoglobulin, MV - mechanical ventilation, NIMV - non-invasive mechanical ventilation, SOFA - sequential organ failure assessment, DM diabetes mellitus, CAD - coronary artery disease, CHF - congestive heart failure, CVD - cerebrovascular disease 
Table 2. Distribution of demographic and clinical variables according to ACE polymorphism

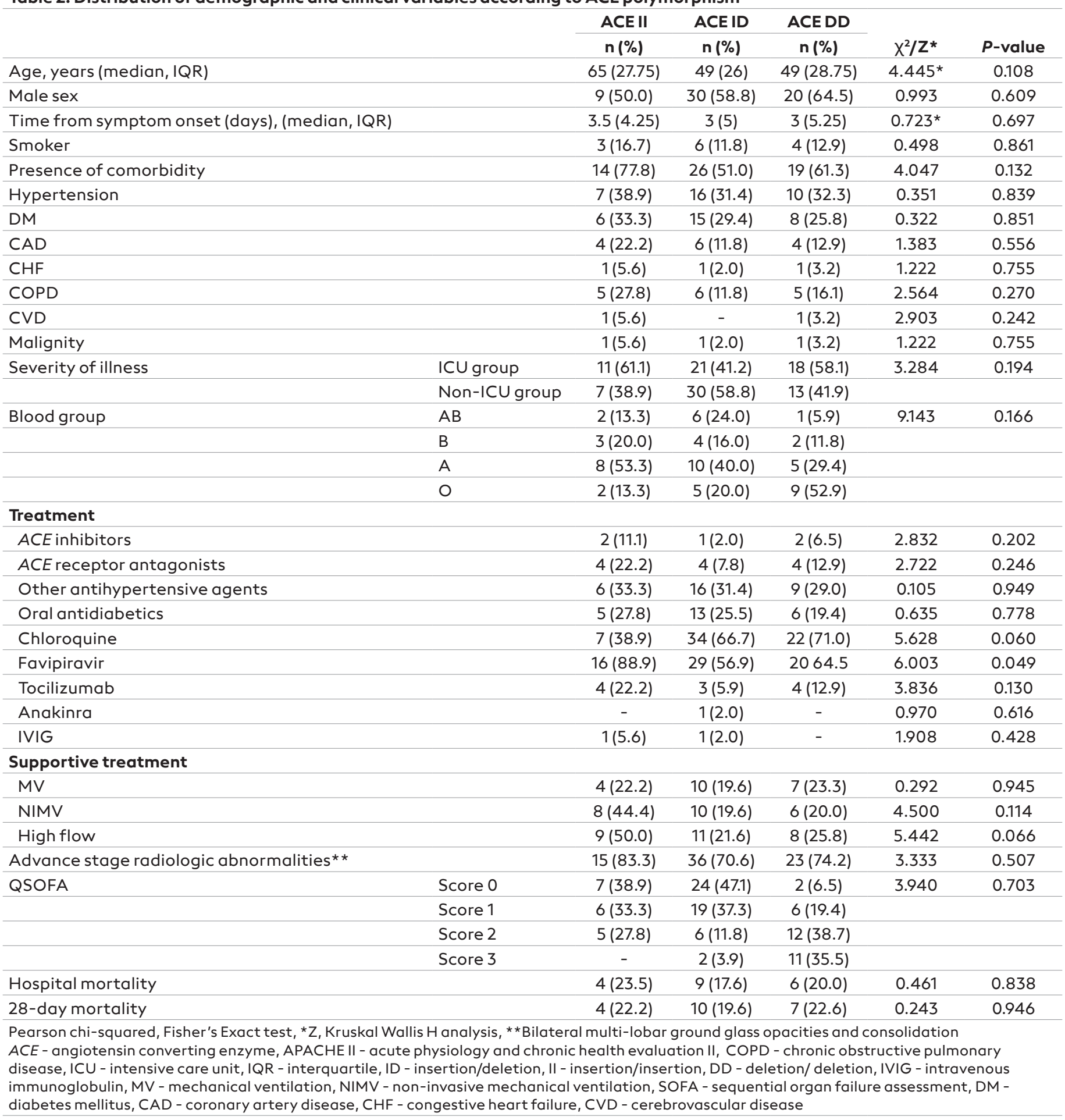

whereas it was $58.1 \%$ for ACE1 DD and $41.2 \%$ for ACE1 ID ( $p>0.05$ ) (Table 2). In patients who had ACE1 ID gene polymorphism, the presence of hypertension was significantly more common in ICU patients $[p=0.002$, Exp $(B)=8.67,95 \%$ $\mathrm{Cl}=2.22-33.83]$. Older age was a significant predictor of ICU requirement in patients with $A C E 1$ ID and DD polymorphism ( $p<0.001$ and $p=0.008$, respectively). Furthermore, there was no difference in terms of age and comorbidities (hypertension, diabetes mellitus, and coronary artery disease) be- tween the ICU and non-ICU groups in patients with ACE1 II polymorphism (Table 5).

\section{Main interventions and treatment}

For antiviral treatment, favipiravir was administered to 65 patients, and chloroquine was given to 63 patients (Table 1). Favipiravir was given to all critically ill patients in the ICU group and to $30 \%$ of the non-ICU group $(n=15)$. Steroid and anticoagulant treatment were not given to patients in the 
Table 3. Binary logistic regression analysis for the effect of variables on ICU requirement

\begin{tabular}{|c|c|c|c|}
\hline & OR & $95 \% \mathrm{Cl}$ & $P$-value \\
\hline \multicolumn{4}{|c|}{$\begin{array}{l}\text { Single binary logistic regression } \\
\text { analysis }\end{array}$} \\
\hline Age, years & 1.09 & $1.05-1.13$ & $<0.001$ \\
\hline Hypertension & 6.65 & $2.52-17.6$ & $<0.001$ \\
\hline DM & 3.80 & $1.48-9.75$ & 0.005 \\
\hline CAD & 4.42 & $1.15-16.97$ & 0.030 \\
\hline $\begin{array}{l}\text { Advanced stage radiologic } \\
\text { abnormalities }\end{array}$ & 20.44 & $4.47-93.47$ & $<0.001$ \\
\hline \multicolumn{4}{|l|}{$\begin{array}{l}\text { Multivariate binary logistic } \\
\text { regression analysis }\end{array}$} \\
\hline \multicolumn{4}{|l|}{ Step 2} \\
\hline Age, years & 1.08 & $1.04-1.13$ & $<0.001$ \\
\hline $\begin{array}{l}\text { Advanced stage radiologic } \\
\text { abnormalities }\end{array}$ & 17.72 & $3.24-96.79$ & 0.001 \\
\hline Constant & 0.00 & & $<0.001$ \\
\hline \multicolumn{4}{|l|}{ Variables not in the equation } \\
\hline & & & $P$-value \\
\hline DM & & 2427.00 & 0.119 \\
\hline Hypertension & & 0.827 & 0.363 \\
\hline CAD & & 0.376 & 0.540 \\
\hline Overall Statistics & & 2961.00 & 0.398 \\
\hline
\end{tabular}

OR - odds ratio, $\mathrm{Cl}$ - confidence interval, DM - diabetes mellitus, CAD coronary artery disease

Table 4. Binary logistic regression analysis for the effect of ACE polymorphism on ICU requirement

\begin{tabular}{lccc}
\hline & Odds ratio & $\mathbf{9 5 \%} \mathbf{C l}$ & $\boldsymbol{P}$-value \\
\hline ACE II & & & 0.197 \\
\hline ACE ID & 0.45 & $0.15-1.34$ & 0.149 \\
\hline ACE DD & 0.88 & $0.27-2.89$ & 0.834 \\
\hline ACE II vs. ID+DD & 0.58 & $0.2-1.64$ & 0.301 \\
\hline ACE ID vs. II+DD & 2.07 & $0.93-4.6$ & 0.073 \\
\hline ACE DD vs. II+ID & 0.62 & $0.27-1.47$ & 0.281
\end{tabular}

$A C E$ - angiotensin converting enzyme, ICU - intensive care unit, ID insertion/deletion, II - insertion/insertion, DD - deletion/ deletion

non-ICU group as there was no known recommendation for their administration at that point in time. It was given only in $41.7 \%(15 / 50)$ of the ICU patients for critical illness related corticosteroid insufficiency solely on the basis of the clinical decision of the ICU specialist. Anticoagulant treatment was implemented in all the patients in the ICU group routinely. Tocilizumab and anakinra were administered in $22 \%(n=11)$ and $2 \%(n=1)$ of the patients, respectively, in the ICU group as an immunomodulatory therapy. Oral antidiabetic treatment and antihypertensive agent usage were significantly higher in the ICU group ( $p=0.005$ for antidiabetic agents, $p=0.014$ for $A C E 1$ receptor antagonists, and $p=0.001$ for other anti-hypertensives).

Among the ICU patients, invasive mechanical ventilation was administered to 21 patients (42\%), non-invasive mechanical ventilation was needed in 24 patients (48\%), and high flow nasal oxygen therapy was required in 28 patients $(56 \%)$. Hospital mortality occurred in 19 patients $(38 \%)$ and
Table 5. Binary logistic regression analysis for the effect of variables on ICU requirement in the patients with ACE II, ACE ID, and ACE DD polymorphisms

\begin{tabular}{|c|c|c|c|}
\hline & OR & $95 \% \mathrm{Cl}$ & $P$-value \\
\hline \multicolumn{4}{|l|}{ ACE II } \\
\hline Age & 1.06 & $0.99-1.14$ & 0.096 \\
\hline Hypertension & 0.76 & $0.11-5.28$ & 0.783 \\
\hline DM & 5 & $0.44-56.62$ & 0.194 \\
\hline CAD & 0.56 & $0.06-5.24$ & 0.608 \\
\hline ACE ID & & - & \\
\hline Age & 1.1 & $1.04-1.16$ & $<0.001$ \\
\hline Hypertension & 8.67 & $2.22-33.83$ & 0.002 \\
\hline DM & 3 & $0.86-10.41$ & 0.083 \\
\hline CAD & 9.06 & $0.97-84.46$ & 0.053 \\
\hline$A C E D D$ & & - & \\
\hline Age & 1.1 & $1.02-1.17$ & 0.008 \\
\hline Hypertension & 2625146654.61 & $0-$ & 0.999 \\
\hline DM & 7.64 & $0.81-72.4$ & 0.076 \\
\hline CAD & 1500083802.98 & $0-$ & 0.999 \\
\hline \multicolumn{4}{|c|}{$\begin{array}{l}\text { ACE - angiotensin converting enzyme, ICU - intensive care unit, ID } \\
\text { - insertion/deletion, II - insertion/insertion, DD - deletion/ deletion, } \\
\text { OR - odds ratio, } \mathrm{Cl} \text { - confidence interval, DM - diabetes mellitus, CAD - } \\
\text { coronary artery disease }\end{array}$} \\
\hline
\end{tabular}

28-day mortality in 21 patients (42\%) in the ICU group (Table $1)$. All the remaining patients clinically improved and were discharged.

\section{DISCUSSION}

ACE2 protein is expressed by the ACE2 gene consisting of 18 exons (Xp22.2) located on the short arm of the X chromosome (11). It was suggested that the cause of higher risk of severe COVID-19 in men may be owing to the lower expression of $A C E 2$ as they have one copy of $X$-linked ACE2 gene (4). However, there are conflicting results regarding the effect of sex on the clinical severity of COVID-19 $(3,12)$. In this study, no significant difference was found between ICU and non-ICU patients in terms of sex.

Older age, the presence of advanced stage radiologic abnormalities, and comorbidities were significantly higher in severe patients as it had been defined previously (3). The blood types were similar between the ICU and non-ICU groups. The effect of blood types on clinical severity found in this study was not in line with the results reported in the literature (13). The ACE2 gene has polymorphic nucleotide changes that can vary in frequency between individuals and populations, and alter the function of the protein expressed. It is thought that these polymorphisms in the ACE2 receptor gene may bind the virus to the host cell and consequently alter its virulence (8). In this study, no polymorphism on exon 1 and 2 of the ACE2 gene was detected.

The polymorphisms of the ACE1 gene, which has $42 \%$ amino acid similarity with $A C E 2$, also affect the expression of ACE2 (14). The ACE1gene is located on the long arm of chromosome 17 and shows the insertion/deletion (ID) polymorphism in the 287 bp Alu repeat region in the 16th intron (15). The frequency of $D$ allele was reported significantly higher in patients with hypoxemic SARS than in non-hypoxemic patients in a small 
cohort of Vietnamese cases (16). Pati et al. (17) conducted an epidemiological study to examine whether a functional I/D polymorphism in the ACE gene is associated with SARSCoV-2 infection via the prevalence of $A C E$ I/D polymorphism reported in 148 studies from various Asian countries. They involved 11 studies (with a total of 1090 individual participants) investigating the prevalence of the ACE1 gene polymorphism in healthy populations in Turkey and reported the frequencies of ACE1 ID, DD, and II genotypes as $46.1 \%, 31.8 \%$, and $22 \%$, respectively. In addition, the frequency of the ' $D$ ' allele was reported as $54.9 \%(n=1197)$ and ' $\mathrm{I}$ ' allele as $45.1 \%$ $(n=983)$ in the same study (17). They concluded that there was a positive correlation between the prevalence of ' $D$ ' allele and the mortality rate of COVID-19 in the population $(r=0.620, p=0.002, n=22)$. However, they suggested further evaluations in hospital-based studies (17). In our cohort, the prevalence of ACE1ID, DD, and II genotypes were found to be similar to that previously reported in a healthy Turkish population as $51 \%, 31 \%$, and $18 \%$, respectively. In this study, the frequency of the D allele was $50.4 \%$ in the ICU group, whereas it was $49.6 \%$ in the non-ICU group, and the difference was not statistically significant ( $p>0.05)$.

The I/D polymorphisms in the intron 16 of ACE1 are associated with changing concentrations of $A C E$ in circulation and tissues. Factors affecting the ACE2 expression may have an impact on COVID-19 outcome (4). There are conflicting data regarding the association of ACE1 DD genotype and an increased risk of respiratory distress syndrome $(16,18)$. Zheng and Cao (5) suggested that the presence of ACE1 DD polymorphism may be responsible for severe lung injury. Yamamoto et al. (1) reported that the prevalence of ACE1 II genotype in the population was negatively correlated with the mortality because of COVID-19. Similarly, ACE1 DD polymorphism was reported to be associated with severe COVID-19, whereas ACE2 polymorphism did not have any effect (4).

ACE2 facilitates rapid viral replication, whereas the depletion of ACE2 from the cell membrane enhances the damaging effects of Ang-II in the lung (19). Delanghe et al. (19) reported a negative correlation between the frequency of ' $D$ ' allele and COVID-19-related mortality. However, it was reported that more studies are required to evaluate the clinical outcome of COVID-19 infection in ACE1DD, ID, and II carriers and to investigate the precise role of $A C E 1$.

To determine the effect of ACE1 gene polymorphisms on COVID-19 severity, ICU and non-ICU patients were compared in this study. There was no statistically significant effect of the DD genotype compared with the II + ID genotypes ( $p>0.05)$. None of the ACE1 genotypes had any effects on severity.

In addition, the ACE1 DD genotype was detected statistically more frequently in hypertensive male patients with severe COVID-19 (4). Therefore, we evaluated the impact of comorbidities such as hypertension, coronary artery disease, diabetes mellitus in relation with the ACE1 II, ID, and DD genotype in the present study. Single logistic regression analysis was performed to analyze the effect of older age and comorbidities on ICU requirement in patients with ACE1 II, ID, and DD polymorphisms. Older age was a significant risk factor for ICU requirement in patients with $A C E 1$ ID and DD polymorphisms. The presence of hypertension was associated with 8.67 times higher risk of ICU requirement in patients with ACE1 ID polymorphism, although there was no association with other comorbidities. Although ACE receptor antagonists and other antihypertensive agents were more frequently used in patients in the ICU, these differences were thought to be the consequences of higher percentage of hypertension in ICU patients. Reynolds et al. (20) reported no positive association between the use of $A C E$ receptor antagonists/ACE inhibitors with severe COVID-19. The generally accepted scientific knowledge is that the use of $A C E$ inhibitors and $A C E$ receptor antagonists does not increase susceptibility to SARS-CoV-2 infection and has no effect on the severity of COVID-19 $(21,22)$. When the frequency of antihypertensive use was evaluated in patient groups with different gene polymorphisms, no difference was found between groups.

\section{Study limitations}

The small size of the study population is the limitation of our study. Large cohorts are needed to define the exact role of ACE gene polymorphism on the severity of COVID-19 pneumonia. Further hospital-based large cohort studies are necessary to assess the exact role of the ACE polymorphism on clinical outcome of COVID-19 pneumonia.

\section{CONCLUSION}

1. ACE1 gene polymorphisms including II, ID, and DD genotypes had no impact on predicting ICU requirement in patients with COVID-19 pneumonia.

2. Single logistic regression analysis revealed that older age is a predictor of ICU requirement in patients with ACE1 ID and DD polymorphisms. The presence of hypertension predicted severity only in patients with ACE1 ID genotype.

3. ACE2 PD variants on exon 1 and 2 were not detected in the study population. We suggest that predictions made with bioinformatics analysis need to be verified with real life experiences and data analysis in different ethnic groups.

4. Older age and the presence of advanced stage radiologic abnormalities on admission were independent predictors of ICU requirement.

Further hospital-based large cohort studies are necessary to assess the exact role of the ACE gene polymorphisms on clinical outcome of COVID-19 pneumonia.

Acknowledgments: We thank the Turkey Infectious Diseases and Clinical Microbiology Specialty Society for their support in conducting this study.

Declaration: The oral presentation of the manuscript was presented at the "9th Congress of Infectious Diseases and Clinical Microbiology Specialty Society of Turkey on 20th to 23rd May, 2021" held online.

Institutional and financial support: This research received a specific grant from Turkey Infectious Diseases and Clinical Microbiology Specialty Society (EKMUD) (Grant number: 08-30.07.2020).

Conflict of interest: None declared. 
Peer-review: Externally peer-reviewed.

Author contributions: Concept - S.B., B.C., A.B., H.B.; Design - S.B., B.C.., A.B., H.B.; Supervision - S.B., B.C., A.B., H.B.; Fundings - S.B., A.B.; Materials - S.B., B.C.., A.B.; Data collection \&/or processing S.B., B.Ç., A.B., I.Ș., E.T., E.Y.Ç., N.K., C.S., D.E., G.G.C., I.Ö.T., S.K., H.B.; Analysis \&/or interpretation - S.B., B.C., A.B., E.T.; Literature search - S.B., B.C., A.B., E.Y.C., N.K., C.S.; Writing - S.B., B.C., A.B.; Critical review - S.B., B.C.., A.B., I.Ş., E.T., E.Y.Ç., N.K., C.S., D.E., G.G.C., I.Ö.T., S.K., H.B.

\section{REFERENCES}

1. Yamamoto $N$, Ariumi $Y$, Nishida $N$, Yamamoto R, Bauer $G$, Gojobori T, et al. SARS-CoV-2 infections and COVID-19 mortalities strongly correlate with ACE1 I/D genotype. Gene 2020; 758: 144944. [Crossref]

2. Saadat M. No significant correlation between ACE Ins/Del genetic polymorphism and COVID-19 infection. Clin Chem Lab Med 2020; 58: 1127-8. [Crossref]

3. Bastug A, Bodur H, Erdogan S, Gokcinar D, Kazancioglu S, Kosovali $B D$, et al. Clinical and laboratory features of COVID-19: Predictors of severe prognosis. Int Immunopharmacol 2020; 88: 106950. [Crossref]

4. Gómez J, Albaiceta GM, García-Clemente M, López-Larrea C, Amado-Rodríguez L, Lopez-Alonso I, et al. Angiotensin-converting enzymes ( $A C E, A C E 2)$ gene variants and COVID-19 outcome. Gene 2020; 762: 145102. [Crossref]

5. Zheng H, Cao JJ. Angiotensin-Converting Enzyme Gene Polymorphism and Severe Lung Injury in Patients with Coronavirus Disease 2019. Am J Pathol 2020; 190: 2013-7. [Crossref]

6. Wang R, Alam G, Zagariya A, Gidea C, Pinillos H, Lalude O, et al. Apoptosis of lung epithelial cells in response to TNF-alpha requires angiotensin II generation de novo. J Cell Physiol 2000; 185: 253-9. [Crossref]

7. Sarangarajan R, Winn R, Kiebish MA, Bountra C, Granger E, Narain NR. Ethnic Prevalence of Angiotensin-Converting Enzyme Deletion (D) Polymorphism and COVID-19 Risk: Rationale for Use of Angiotensin-Converting Enzyme Inhibitors/Angiotensin Receptor Blockers. J Racial Ethn Health Disparities 2021; 8: 973-80. [Crossref]

8. Suryamohan K, Diwanji D, Stawiski EW, Gupta R, Miersch S, Liu J, et al. Human ACE2 receptor polymorphisms and altered susceptibility to SARS-CoV-2. Commun Biol 2021; 4: 475. [Crossref]

9. World Health Organization. Clinical management of severe acute respiratory infection (SARI) when COVID-19 disease is suspected: interim guidance, 13 March 2020. World Health Organization. Available from: URL: https://apps.who.int/iris/handle/10665/331446. [Crossref]

10. Yoshida H, Mitarai T, Kawamura T, Kitajima T, Miyazaki Y, Nagasawa $\mathrm{R}$, et al. Role of the deletion of polymorphism of the angiotensin converting enzyme gene in the progression and therapeutic responsiveness of IgA nephropathy. J Clin Invest 1995; 96 : 2162-9. [Crossref]
11. Tipnis SR, Hooper NM, Hyde R, Karran E, Christie G, Turner AJ. A human homolog of angiotensin-converting enzyme. Cloning and functional expression as a captopril-insensitive carboxypeptidase. J Biol Chem 2000; 275: 33238-43. [Crossref]

12. Palaiodimos L, Kokkinidis DG, Li W, Karamanis D, Ognibene J, Arora $S$, et al. Severe obesity, increasing age and male sex are independently associated with worse in-hospital outcomes, and higher in-hospital mortality, in a cohort of patients with COVID-19 in the Bronx, New York. Metabolism 2020; 108: 154262. [Crossref]

13. Göker $H$, Aladağ Karakulak E, Demiroğlu H, Ayaz Ceylan ÇM, Büyükașik $Y$, Inkaya $A C ̧$, et al. The effects of blood group types on the risk of COVID-19 infection and its clinical outcome. Turk J Med Sci 2020; 50: 679-83. [Crossref]

14. Donoghue M, Hsieh F, Baronas E, Godbout K, Gosselin M, Stagliano $N$, et al. A novel angiotensin-converting enzyme-related carboxypeptidase (ACE2) converts angiotensin I to angiotensin 1-9. Circ Res 2000; 87: E1-9. [Crossref]

15. Rigat B, Hubert C, Alhenc-Gelas F, Cambien F, Corvol P, Soubrier $F$. An insertion/deletion polymorphism in the angiotensin I-converting enzyme gene accounting for half the variance of serum enzyme levels. J Clin Invest 1990; 86: 1343-6. [Crossref]

16. Itoyama S, Keicho N, Quy T, Phi NC, Long HT, Ha LD, et al. ACE1 polymorphism and progression of SARS. Biochem Biophys Res Commun 2004; 323: 1124-9. [Crossref]

17. Pati $\mathrm{A}$, Mahto $\mathrm{H}$, Padhi $\mathrm{S}$, Panda AK. ACE deletion allele is associated with susceptibility to SARS-CoV-2 infection and mortality rate: An epidemiological study in the Asian population. Clin Chim Acta 2020; 510: 455-8. [Crossref]

18. Matsuda A, Kishi T, Jacob A, Aziz M, Wang P. Association between insertion/deletion polymorphism in angiotensin-converting enzyme gene and acute lung injury/acute respiratory distress syndrome: a meta-analysis. BMC Med Genet 2012; 13: 76. [Crossref]

19. Delanghe JR, Speeckaert MM, De Buyzere ML. COVID-19 infections are also affected by human ACE1 D/I polymorphism. Clin Chem Lab Med 2020; 58: 1125-6. [Crossref]

20. Reynolds HR, Adhikari S, Pulgarin C, Troxel AB, Iturrate E, Johnson $\mathrm{SB}$, et al. Renin-Angiotensin-Aldosterone System Inhibitors and Risk of Covid-19. N Engl J Med 2020; 382: 2441-8. [Crossref]

21. American College of Cardiology. HFSA/ACC/AHA statement addresses concerns re: using RAAS antagonists in COVID-19. March 17, 2020. Available from: URL: https:/www.acc.org/ latest -in -cardiology/ articles/2020/03/ 17/ 08/ 59/ hfsa-acc-aha -statement -addresses -concerns -re-using-raas-antagonists -in-covid-19.

22. European Society of Cardiology. Position statement of the ESC Council on Hypertension on ACE-inhibitors and angiotensin receptor blockers. March 13, 2020. Available from: URL: https:/ www.escardio.org/Councils/Council-on-Hypertension-(CHT)/ News/ position-statement-of-the-esc-council-on-hypertension-on-ace-inhibitors-and-ang. 